\title{
Lens Application: Mobile Application Using Augmented Reality
}

\author{
https://doi.org/10.3991/ijim.v14i02.11726
}

\author{
Nahla Aljojo ( $\left.{ }^{\bowtie}\right)$, Asmaa Munshi, Azida Zainol, Rahaf Al-Amri, \\ Anan Al-Aqeel, Maram Al-khaldi, Manar Khattabi \\ University of Jeddah, Jeddah, Saudi Arabia \\ nmaljojo@uj.edu.sa \\ Jamal Qadah \\ King Abdulaziz University, Jeddah, Saudi Arabia
}

\begin{abstract}
Smartphones and Mobile App are acceptable as learning tool, especially related to history which control the present and build the future; particularly the study of history is the practical application of the Qur'an and the Sunnah. The history subject, specifically on the stories of the prophets contains many lessons and wisdoms give values that are transformed into the child's mind and translated into his/her behavior. In Saudi Arabia elementary schools, history is firstly introduced to fourth grade that contains the stories of the prophets, may not get the strong impact of the story in soul and memory when they only read it from the book with simple pictures of the story places, thus they might not enjoy and get the required values from those precious stories. For the teachers, it is hard and difficult to ensure that students imagined and understood the story in the right way. Hence, in order to facilitate the learning of these topics, the objective of this paper is to develop a mobile application with visual-learning style to help in improving children imagination of the stories with 3D characterslitems using augmented reality technology. The methodology involves analysis, design, implementation and testing. The result of this project is an education tool that helps the teachers in their teaching environment and improves the students learning process. Therefore, the result of this project has contributed to the educational for young children in Saudi Arabia; towards the development of knowledge society to achieving Saudi Arabia Vision 2030.
\end{abstract}

Keywords - 3D Model, Augmented Reality, Mobile Application

\section{Introduction}

The kingdom of Saudi Arabia has the vision of 2030 [1] which is long-term goals and expectations that supposed to be achieved by applying specific programs. 
"National Enrichment Character Program" that is one of the vision's programs that aims to build better society by enriching the characters of the citizens. The education is important for everyone's future and giving it in the right way will make it easier to be understood by the students and let them get the benefit of the subject. The first thing that most people will do when they face problem in understanding their subject is using technology to try different methods in explaining the topic they want to understand or get better understanding about it and look for entertaining methods if the students are children.

Nowadays, smart mobile devices compared with other digital devices are the most popular among young children [2]. International research indicates that these devices can be used as an educational tool [2], [3]. Hence, we the educational application developed on mobile phones are important to educate young children.

Focusing on history subject, specifically on the stories of the prophets that contains a lot of lessons and wisdoms which should give values that help children grow up properly, these values are transformed into the child's mind and translated into his/her behavior. The fourth grade students of elementary schools, who has the first history subject level that contains the stories of the prophets, may not get the strong impact of the story in soul and memory when they only read it from the book with simple pictures of the story places, thus they might not enjoy and get the required values from those precious stories. For the teachers, it could be hard and difficult to ensure that students imagined and understood the story in the right way. Hence, in order to facilitate the learning of these topics, a mobile application with visual-learning style is developed to help improve children imagination of the stories with 3D characterslitems using augmented reality technology.

The main purpose of this project is to improve learning process and make it more entertaining for students by developing an application with Augmented Reality technology and by engaging taxonomy of cognitive objectives, Bloom's Taxonomy [4] to educate stories of the prophets to achieve the Saudi Vision 2030 by enhancing "National Character Enrichment" program that is one of the 2030 Vision programs. The main objectives are to make history learning more entertaining for fourth grade students of elementary schools by interacting with 3D items from important places in Islamic historical events and prophets' stories that will improve in learning process for both students and teachers in different ways:

- Develop and strengthen the national identity of individuals to develop and raise students on Islamic values, which protects the generation of religious, social, cultural and media threats to achieve the Saudi Vision 2030 by enhancing "National Character Enrichment" program that is one of the 2030 Vision programs

- Improve learning by entertainment by adding technologies in classrooms for student's elementary schools

- Improve learning by adding educational tool for teachers to help their students to understand and visualize the historical items/places in a better way

- Improve the group work in classrooms by focusing on shared 3D items that enable students at the same time to see their friends face to face in reality

- Transfer book information from static to interactive items 
- Capture student attention to learning by visualizing objects

- Make students interact more effectively by seeing the 3D items from different angles

The scope of the project is to develop a 3D items using Augmented Reality for the social and national education book for the fourth grade students of elementary schools that contains the Islamic history events and prophets' stories to help students understand and visualize the historical places. Further, teachers can use this application to improve their teaching process. As a result, this project purposely to make prophets stories more entertaining for the fourth grade students of elementary schools by using augmented reality to visualize the historical prophets' stories for letting the students get the whole value while enjoying seeing the story or the historical items/places. Also, how our project will be part of realizing the vision of 2030 by supporting the "National Character Enrichment Program".

\section{Literature Review}

Empirical learning can be applied through using AR technology that supplement the existing world for students instead of virtual world. Increase the evolution of AR in by using smart devices, which became a part of everyone's life that facilitate completing tasks of any type. Combining such technology that students use easily and learning, allows students to learn in their houses, resulting in making students be engaged effectively and participated in an experience that is provided by augmented reality in teaching and learning. Thus, students can memorize the information easily and obtain the full value of it [5].

This section explores the vision of 2030, Technology in teaching and the classroom, History Augmented Reality-based learning, Theoretical framework and Related Work.

\section{$2.1 \quad$ Vision 2030}

The vision was developed by the Council of Economic and Development Affairs, which are chaired by Deputy Crown Prince Mohammed bin Salman. It includes goals and strategies for the Kingdom's long-term economic success and development of public service sectors such as education [1]. To build the best future for the kingdom, vision had based on three themes that represent the kingdom's competitive advantages: a vibrant society, a thriving economy and an ambitious nation.

In addition to 12 programs called Vision Realization Programs (VRPS) created to achieve the target of the vision. The VRPs are: Enriching the Hajj and Umrah Experience Program, National Transformation Program, Public Investment Fund Program, National Industrial Development and Logistics Program, Financial Sector Development Program, Lifestyle Improvement Program, National Companies Promotion Program, Strategic Partnerships Program, The Housing Program, 
Privatization Program, Saudi Character Enrichment Program, Fiscal Balance Program [1]

\subsection{Technology in teaching and the classroom}

The potential of technology have intrigued the educators to improve learning of students and to help education transformation, since the birth of the motion picture in 1922, to the computer advent in the mid-1970s [6]. Education research studies demonstrate the benefits of the use of technology in schools classrooms, and they are [6]:

- Technology can be helpful in improving the students' scores on standardized tests, e.g., computers.

- Improve students' thinking in inventive ways, e.g., problem solving.

- Student self-concept and motivation will improve.

Positively impact by technology belief has led multiple governments to develop programs for technology schools integration. School districts in the US (United States) reportedly spent $7.87 \$$ billion during the 2003-2004 school year on technology equipment [6]. Although technology plays important role in education, there is important to ensure it the apps are designed in accordance with developmentally appropriate standards to contribute to the social, emotional and cognitive development of children in formal and informal learning environments. A study by [3] has shown that there are educational apps that unable to contribute to a deeper conceptual understanding of certain concepts.

\subsection{History Augmented Reality-based learning}

AR in education: At schools and business environment the AR (augmented reality) has been experimentally applied, but it's not as much as the classic methods of education and training in the past two decades [7]. Technologies become more powerful to make AR possible than ever before. The increase of wireless mobile devices, such as tablets and smart phones, led the AR into the mobile space offering great deals by applications especially in education and training areas [7]

History learning based on AR: AR technology can make the book "magical", and that is our goal with history primary school students' books. A study by [8] had determine that people specifically young children can be more interactive and realistic in reading books by rendering 3D models onto books using AR technology. This way called "The Magic-Book" that is about enabling people fantasies to become a part of the story a reality by using both original books and AR handheld device. Children can see three-dimensional modules from Islamic historical stories and travel to the story important places [7].

Some details of mobile augmented reality potentials for education has been given in Nincarean, Alia, Halim, \& Rahman (2013), however over the years many research studies present and empirically tests on how individual perceive and evaluate the 
benefits and augmentation quality of AR apps especially as related to education [10]. Although AR plays a huge impact on games, especially some years back, for example 'Pokémon Go' where users catch virtual creatures projected over the real-world [11], in which it leads to augmented reality marketing raised higher [12]. Research shows how and why consumers AR drives consumer decision making [12], [13]. Similarly, a study by [14] argues that virtual reality can provide an alternative setting that combines the benefits. This study [14] examines the effects of lead-usership on the acceptance of media innovations of mobile augmented reality and reveals that users with high lead-usership scores tend to a higher behavioral intention to use a media innovation. Another study by [15] examines the characteristics of mobile augmented reality apps from the system and architecture perspective and reveal that mobile augmented reality apps implementations are mostly CPU intensive.

\subsection{Theoretical framework}

Bloom's taxonomy of learning domains: Bloom and his colleagues established the most widespread classifications in formulating, identifying objectives and the classification divides the objectives into three areas [4], [16]:

- Cognitive domain

- Affective domain

- Psychomotor domain

Bloom was interested in dividing the cognitive domain, and gave most of his attention to other spheres, which is where we will focus. It concentrates on capacity or mental processes that relate to knowledge of facts, the operations of understanding and remembering, and discovering methods of identifying information and building concepts, principles, and generalizations [4]. Benjamin Bloom divided this area into six graded levels, from simple to complex, as shown in Figure 1.

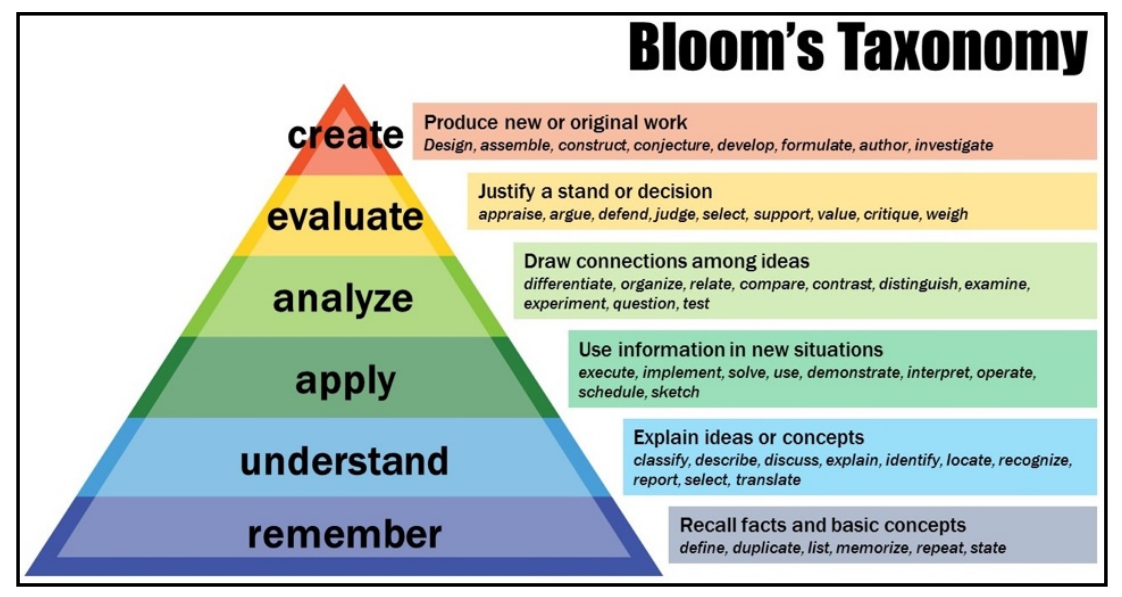

Fig. 1. Bloom's Taxonomy of Cognitive Goals[4], [16] 


\subsection{Related Work}

Sky guide is an application enable you to get information about everything you see in the sky and lets you locate stars, constellations, satellites, planets and more by using augmented reality through the camera Sky Guide [17]. Sky Guide provides powerful features for all ages and experience levels. It also makes learning about the sky clear and effortless. It makes application used anywhere and works with or without Wi-Fi. It provides a detailed summary of visible satellite passes, and planets and finally, it provides a calendar of future astronomical events. Sky Guide is compatible with iPhone, iPad, and iPod touch. They help users show notifications that proactively there to key events such as eclipses. Show them the interesting activity in the sky when they swipe up. Augmented reality is used to find stars, constellations, and planets easily by clicking the centre button to turn motion on and then you will see a new camera button appear.

Zoo-AR [18] is an Augmented Reality application that helps kids to interact with the animals and learn about them. The typical zoo, information is conveyed through printed text, some photos, and looping video. The system provides students with more hands-on manipulative that pushes that learning to the next level. It also provides a 3D environment that able kid to see what's happening. This system can make kids interact with animals like take a picture with them. The application is currently available on both IOS and Android devices it uses these devices because they are tamper-proof, very resilient and most of all safe. Zoo-AR used many of augmented reality technology, there are: Layar is one of leaders in creating a platform for AR. It is as a way to show where objects were when holding the camera up towards a certain direction. Aurasma is another company that makes it easy for anyone to create and use AR. String is a developer technology that enables for image using developer specified images and track reasonably fast and in full 3D. Vuforia is an exciting open source technology from Qualcomm that it allows developers to create applications that can see real world objects.

Aug that [19] is an Augmented Reality application that helps students, teachers, and parents make education fun and interactive.it is containing 3-Dimensional shapes for classroom workshops, videos lessons, or websites to direct users to educational help. The application provides a meaningful and technological experience for learning that will drive student growth. It provides auditory learners by making students can hear directions read out loud. It also provides visual Learners by making students can view the object and manipulate the perspective. It is works on any tablet or smartphone (iPad, iPhone, Android Phone, Android tablet). The CEO of the Aug That application called Adam Newman said: "Augmented reality is more cost-effective for a school district. When I look at augmented reality, it is starting to become more mainstream. " $[20]$.

AR-3D science [21] is another existing system for science interactive and most advanced educational tool by using markers as pointing devices. The objects covered in this system include Physics, Biology, and Chemistry. It is design and construct an Augmented Technology App for educational purpose in learning the fundamental concepts of AR Biology, AR Chemistry and AR Physics for Science in the schools. It 
works on Android phone and Android tablets. Student can view Object in life like 3D Object in 3D View section of App. Interactive Feature of app allows Students to Touch, Pinch In - Pinch Out, Rotate the Model. Strong UI/UX and Graphical Presentation of Objects create excitement to learn again and again. It gives Textual Information to know more details about Each Elements. App has AUGMENTED REALITY (AR) mode where Objects will pop up Live on Mobile Screen with Interactive features. Professional Voice Over adds real time Immersion and changing the learning process very simple and Long Lasting from Student point of view.

AR flashcards [22] is another existing system. It is used to learn animal alphabets to make learning fun with Augmented Reality. It has 26 beautifully rendered animals to learn the alphabet. The app pronounces the letter and name of the animal when tapped on. AR Flashcards are a new way to interact and make Flash cards more entertaining for toddlers and pre-schoolers. When you point your device at the printed flashcard a beautifully rendered 3D animal will pop up on the screen. Tap the animal to hear the letter and animal name. The application is currently available on both IOS and Android devices.

\subsection{Comparison between applications}

This section explores the comparison between applications. See Table 1.

Table 1. Comparisons of applications

\begin{tabular}{|c|c|c|}
\hline Objectives & Description & Applications \\
\hline $\begin{array}{l}\text { The objectives were to provide } \\
\text { powerful features for all ages } \\
\text { and experience levels, a detailed } \\
\text { summary of visible satellite } \\
\text { passes and planets, and a } \\
\text { calendar of future astronomical } \\
\text { events. Makes learning about } \\
\text { the sky clear and effortless, and } \\
\text { the application used anywhere } \\
\text { and works with or without Wi- } \\
\text { Fi. }\end{array}$ & $\begin{array}{l}\text { It is an application enable you } \\
\text { to get information about } \\
\text { everything you see in the sky } \\
\text { and lets you locate stars, } \\
\text { constellations, satellites, planets } \\
\text { and more by using augmented } \\
\text { reality through the camera. }\end{array}$ & Sky Guide [17] \\
\hline $\begin{array}{l}\text { The objectives were to provide } \\
\text { students with more hands-on } \\
\text { manipulative that push that } \\
\text { learning to the next level and } 3 \mathrm{~d} \\
\text { environment that able kids to } \\
\text { see what's happening and } \\
\text { interacts with animals. }\end{array}$ & $\begin{array}{l}\text { It is an Augmented Reality } \\
\text { application that helps kids to } \\
\text { interact with the animals and } \\
\text { learn about them. The typical } \\
\text { zoo, information is conveyed } \\
\text { through printed text, some } \\
\text { photos, and looping video. }\end{array}$ & Zoo-AR [18] \\
\hline $\begin{array}{l}\text { The objectives were to provide } \\
\text { a meaningful and technological } \\
\text { experience for learning that will } \\
\text { drive student growth, auditory } \\
\text { learners by making students can } \\
\text { hear directions read out loud, } \\
\text { visual Learners by making } \\
\text { students can view the object and } \\
\text { manipulate the perspective. }\end{array}$ & $\begin{array}{l}\text { It is an Augmented Reality } \\
\text { application that helps students, } \\
\text { teachers, and parents make } \\
\text { education fun and interactive.it } \\
\text { is contains 3-Dimensional } \\
\text { shapes for classroom } \\
\text { workshops, videos lessons, or } \\
\text { websites to direct users to } \\
\text { educational help. }\end{array}$ & Aug That [19] \\
\hline The objective of this Interactive & Augmented Reality App for & AR-3D Science [21] \\
\hline
\end{tabular}




\begin{tabular}{|c|c|c|}
\hline $\begin{array}{l}\text { Educational AR App is to } \\
\text { design and construct an } \\
\text { Augmented Technology App } \\
\text { for educational purpose in } \\
\text { learning the fundamental } \\
\text { concepts of AR Biology, AR } \\
\text { Chemistry and AR Physics for } \\
\text { Science in the schools. }\end{array}$ & $\begin{array}{l}\text { Science Interactive and Most } \\
\text { Advanced Educational Tool by } \\
\text { using markers as pointing } \\
\text { devices. The Objects covered in } \\
\text { this system include Physics, } \\
\text { Biology, and Chemistry. }\end{array}$ & \\
\hline $\begin{array}{l}\text { AR Flashcards are a new way to } \\
\text { interact and make Flash cards } \\
\text { more entertaining for toddlers } \\
\text { and preschoolers. When you } \\
\text { point your device at the printed } \\
\text { flashcard a beautifully rendered } \\
\text { 3D animal will pop up on the } \\
\text { screen. Tap the animal to hear } \\
\text { the letter and animal name. }\end{array}$ & $\begin{array}{l}\text { AR Flashcards are used to learn } \\
\text { animal alphabets to make } \\
\text { learning fun with Augmented } \\
\text { Reality. It has } 26 \text { beautifully } \\
\text { rendered animals to learn the } \\
\text { alphabet. The app pronounces } \\
\text { the letter and name of the } \\
\text { animal when tapped on. }\end{array}$ & $\begin{array}{l}\text { AR Flashcards - Animal } \\
\text { Alphabet [22] }\end{array}$ \\
\hline
\end{tabular}

\section{$3 \quad$ Methodology}

The methodology for this project is designed purposely to achieve the project objective, so the phases involve are analysis, design, implementation and testing.

\subsection{Analysis}

In this phase, we conducted the data collection, data analysis and requirements analysis using Unified Modeling Language.

Data collection for our project is conducted through online survey that was prepared for teachers who are one of the main users for our application. The form was created using SurveyMonkey website [23] with 10 questions. The survey has been distributed through group massages to reach teachers as many as possible from different areas in Saudi Arabia. The sample of respondent teachers was 92. The survey focused on collecting data about using technology in learning process by teachers to know how helpful would be our application for teachers.

Functional requirements describe what the system should do. In other words, functional requirements describe system behavior under specific conditions. The requirements of the application and the actors are as following:

- Allow admin to monitor and manage the application to solve any problems if existed.

- Allow admin to update the application if any updates are required for security purpose or updates to user interface.

- Allow admin to add, edit and delete content.

- Allow student to answer questions.

- Allow user to skip the opening video.

Non-functional requirements describe how the system works. In other words, describe how a system must behave and what constraints there are on its functionality. The essential non-functional requirements in the following: 
- Performance: Fast response time, when the user makes application loading, and refresh time.

- Accessibility: Makes user able to navigate between pages easily by provides button in each page.

- Ergonomic: intended to provide comfort by making it does not required user efforts while using.

- Simplicity: Should provide the user interface easy to understand.

Hardware that we use it to develop, implement and testing the project are laptop, desktop computer and Smart phones - phone that use Google play store. We used $\mathrm{C} \#$ as a programming language in writing the codes. In addition, the following programs are used to implement the application:

- Visual Studio 2017

- Unity [24]: Is the program used to create real time 2D, 3D, and AR interactive experiences and visualizations and it has tools to offer incredible possibilities for game developers.

- Vuforia [25]: Is a cross-platform Augmented Reality (AR) application development platform and performance on a set of hardware and supports many third-party devices.

\subsection{Design}

The design phase, which helps in understanding requirements delivered by analysis, phase and transfers these requirements into an architecture chart. This architecture chart determines the components, their interfaces, and behaviors. Also, it helps to answers the question about how to build the best solution. In this phase, we will also develop the prototypes [26]. The purpose of the design phase to construe the interface to enable the user to run the system and its functions [27].

Prototype design involve a prototype is an original model, form or an instance that serves as a basis for other processes. In software technology, the term prototype is a working example through which a new model or a new version of an existing product can be derived. A prototype has many benefits, such as the developer and the implementer getting valuable feedback from the user even before the actual project is started [28].

Designing low fidelity prototype known as low-tech, is a simple and easy translation of the product and design concepts. It's used to turn the design ideas into testable and tangible artifacts, collecting and analyzing the user demands at the early stage [29]. It involves :

- Main screens: The main screen contains the application's name and an animation video plays when we click on it explaining the "National Identity Enhancement" program and how it's realized in Vision 2030 through our application. See Figure 2

- Camera screen: After watching Vision 2030 animation video the camera opens for the user to select their target on the book, after pointing the camera to the 
selected target a 3D object will pop-up for the user and a question related to the object for the students to answer, also the student can see the correct answer by clicking on "Answer" button. After clicking on "Answer" button it will show the correct answer for the asked question, the thumps-up button will take the user to the Camera screen. See Figure 3

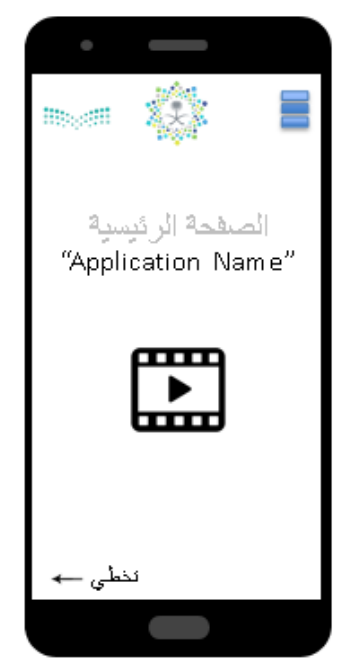

Fig. 2. Main Screen of Application

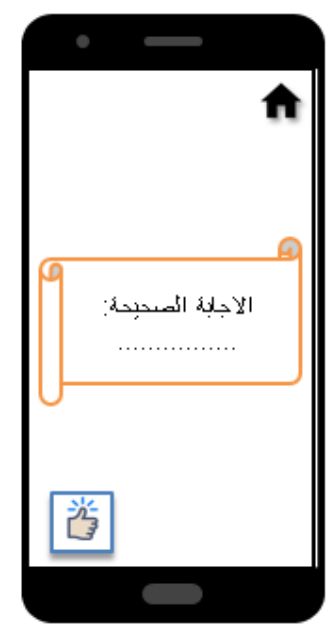

Fig. 3. Camera Screen 
Designing high fidelity prototype to help users to look and feel how the application interface will be. Prototypes help in examining design problems and evaluating solutions [29].

Database design can be defined as related collection of data. We mean by data is known facts that have implicit meaning and can be recorded. Database has several properties; database sometimes called the universe of discourse (UoD) because it represents some aspects of the real world, logically database is a collection of data, and for specific purpose the database is designed, built, and populated with data [30]. Thus, we conducted logical database design and physical database design.

User interface design helps the user to implement what he/she wants to build applications that meet their needs and that are easy to use. [31]. The user interface design for this application is based on the following principles [32]:

The structure principle: The design should be organized the user interface purposefully, based on clear and consistent models which are recognizable to users.

The simplicity principle: The design must make simple to do the common tasks, providing the good shortcuts, which are meaningfully, and commentating clearly in the user's own language.

The visibility principle: The design must keep all necessary materials and options visible without distracting the users by inessential and redundant information. Good designs don't require many alternatives or confuse them with unnecessary information.

The feedback principle: The design must keep users informed through clear and brief language familiar to users about all actions, changes of state, and errors or exceptions that are related to the users.

The reuse principle: The design must reuse the internal and external behaviors and components, so that will be reducing the need to the user to rethink or remember.

\subsection{Implementation}

The implementation of this application as an assistant tool in schools and for students and teachers are based on three principles. First, the theory of Bloom's taxonomy of learning domain who divided the learning area into six graded levels and we focused on the first three levels: Remember, understand and apply where the 3D models in the application will help students to see and imagine the story then it will be easier to remember and apply by answering the attached questions. Secondly, similar applications that focused on learning the children in an entertaining and effective way because it can attract their attention and concentration. Thirdly, the application is based on the vision 2030 that has the objective of "improving the basic learning outcomes" as one of many objectives for "Saudi Character Enrichment" program.

Walkthrough the system: The application consists of the following and the interfaces are shown in the figure XX below:

- Start page: This page contains a "Start" button to start the AR experience 
- Video page: This page displays a short video, which is talking about the idea of our project, our application goal and how we implemented the Vision2030, the video also contains a "Skip" button to give the user the choice to skip the video

- Help page: This page displays how to use our application

- 3D models \& questions pages: Our application consists of many of the pages that contain a single 3D model appear when orienting the camera on the target in the book. At the same time, the user can see the question with an answer box

- Answering page: This page displays the right answer to the given question

\section{$3.4 \quad$ Testing}

In testing phase, we conducted two type of testing. The first testing is known as black box testing which is focusing on testing software from the user perspective to test the functional requirements [33]. Secondly, we are interested to investigate if the application has improved the outcome of the learning process. Thus, we conducted a test session by comparing the means of data from two related samples; say, observations before and after an intervention on the same participant; comparison of measurements from the same participant using Paired t-test measurement technique.

Black box testing method: In the black box testing, we choose the functional testing to test the functional requirements. Thus, the following steps are carried out [33] :

- The functional requirements and specifications of the system are examined

- Tester chooses valid inputs (positive test scenario) to check whether the application can processes them correctly. Also, some invalid inputs (negative test scenario) are chosen to verify that the application is able to detect them

- Tester determines expected outputs for all those inputs

- Software tester constructs test cases with the selected inputs

- The test cases are executed

- Software tester compares the actual outputs with the expected outputs

- Defects if any are fixed and re-tested

Learning outcome test method: Participants and study design. The objective that we wanted to achieve is improving the outcome of the learning process and contribute in resulting in making the information received by the student is well-understood and easy to be remembered by visualizing the main idea of the lesson to make them able to use more of their senses. We had tested our app by visiting the 63rd school which is governmental female school in Jeddah on to test the running application on 40 students of the 4th grade. We applied the pre-test and post-test on the participated students and recorded their scores. The test starts on March 2019.

Learning outcome test method: Paired t-test. Pre-Test Exam: we asked the teacher to give the students the covered lessons by our app in the traditional way, then we gave them a paper that contained four questions, one from each lesson and made the participants take the exam to record their scores. Post-Test Exam: we showed the participants how to use our application to see the 3D objects in each lesson and 
explain how it relates to the lesson, then we gave them another paper with same questions again to record their scores and compare it with the scores that come from the traditional way of learning without visualizing the lessons [34]. Thus, the hypotheses can be expressed as

- H0: There is no difference in mean pre-test and post-test

- H1: There is a difference in mean pre-test and post-test

\section{$4 \quad$ Results and Discussions}

\subsection{Data analysis}

This section describes the data analysis and result of this project. We have conducted an online survey particularly to understand the needs and opinions for this application from the teachers' perspective. Figure 4 shows that 8 with $29.3 \%$ males and 84 with $91 \%$ were Female, 7 with $7.6 \%$ were first level, 6 with $6.5 \% \%$ were second level , 15 with $16.3 \% \%$ were third level, 37 with $40.3 \% \%$ were forth level, 5 with $5.4 \%$ were fifth level, and 22 with 23.9 were sixth level.

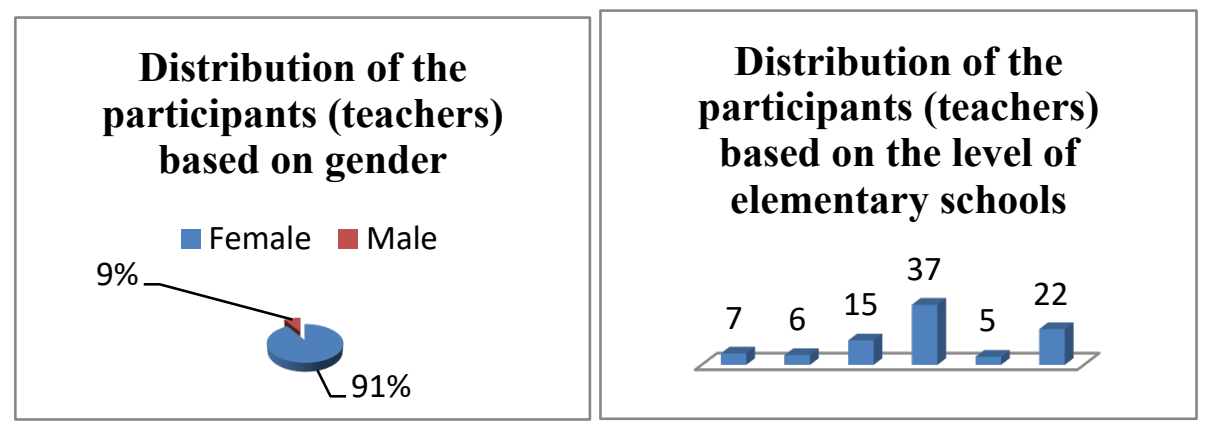

Fig. 4. The Distribution of demographic data in the study group $(n=92)$

Table 2. Ranking Analysis of the Likert-Type Scale (Teachers' answers) (N=92)

\begin{tabular}{|l|c|c|c|c|c|c|c|c|}
\hline \multicolumn{1}{|c|}{ Questions } & $\begin{array}{c}\text { Yes } \\
\text { \% }\end{array}$ & No \% & & & & & & \\
\hline $\begin{array}{l}\text { 1- Have you ever used an educational application } \\
\text { that helps you teach students scientific subject } \\
\text { (social and national education)? }\end{array}$ & 64.1 & 35.9 & & & & & \\
\hline & $\boldsymbol{S} \boldsymbol{A} \%$ & $\boldsymbol{A} \%$ & $\boldsymbol{N} \%$ & $\boldsymbol{D} \%$ & $\boldsymbol{S ~ D} \%$ & $\boldsymbol{M}$ & $\boldsymbol{S} \boldsymbol{D}^{*}$ & $\boldsymbol{A}$ \\
\hline $\begin{array}{l}\text { 2- Are traditional teaching methods used in schools } \\
\text { to teach scientific material (social and national } \\
\text { education) sufficient to understand the material? }\end{array}$ & 4.3 & 22.8 & 52.2 & 16.3 & 4.3 & 3.06 & 0.861 & $\mathrm{~N}$ \\
\hline 3- I have difficulty in clarifying the information to & 6.5 & 29.3 & 45.7 & 15.2 & 3.3 & 3.2 & 0.89 & $\mathrm{~N}$ \\
\hline
\end{tabular}




\begin{tabular}{|l|l|l|l|l|l|l|l|l|}
\hline students in traditional teaching methods. & & & & & & & & \\
\hline 4- Students spend long time using smart devices. & 39.1 & 50 & 4.3 & 3.3 & 3.3 & 4.18 & 0.91 & $\mathrm{~A}$ \\
\hline $\begin{array}{l}\text { 5 - I support the idea of creating an educational } \\
\text { application that helps in teaching students the } \\
\text { scientific material (social and national education) } \\
\text { using the augmented reality technology and 3D } \\
\text { images. }\end{array}$ & 38 & 50 & 7.6 & 4.3 & 0 & 4.2 & 0.76 & $\mathrm{~A}$ \\
\hline $\begin{array}{l}\text { 6 The use of smart devices for students in schools } \\
\text { helps to develop students' abilities and speed of } \\
\text { assimilation of scientific material (social and } \\
\text { national education). }\end{array}$ & 25 & 44.6 & 22.8 & 6.5 & 1.1 & 3.85 & 0.9 & $\mathrm{~A}$ \\
\hline $\begin{array}{l}\text { 7 Electronic educational applications are better } \\
\text { than educational books in the teaching students the } \\
\text { scientific material using technology of augmented } \\
\text { reality and 3D images. }\end{array}$ & 23.9 & 42.4 & 22.8 & 7.6 & 3.3 & 3.76 & 1 & $\mathrm{~A}$ \\
\hline
\end{tabular}

$\begin{array}{ll}\text { S A } & \text { Strongly Agree } \\ \text { A } & \text { Agree } \\ \text { N } & \text { Neutral } \\ \text { D } & \text { Disagree } \\ \text { S D } & \text { Strongly Disagree } \\ \text { S D* } & \text { Standard Deviation } \\ \text { A } & \text { Attitude }\end{array}$

The data shown in Table 2 are the opinion of those teachers about using smart technology such as augmented reality in teaching, especially the subject of social and national education. In addition, we had asked them if they have any suggestions they would like to apply in the teaching process, most answers was about using technology to help teacher and adding fun to the teaching process to engage students and increase their excitement, Beside suggestions about making trips to historical places which may have bigger impact on students to understand and remember the lesson.

\section{$5 \quad$ Result}

The results of this project is an application that facilitate the Augmented Reality technology and engaging taxonomy of cognitive objectives, Bloom's Taxonomy to educate stories of the prophets in fourth grade students of elementary schools in order to achieve the Saudi Vision 2030 by enhancing "National Character Enrichment" program that is one of the 2030 Vision programs. Figure 5 shows the sequence of interfaces.

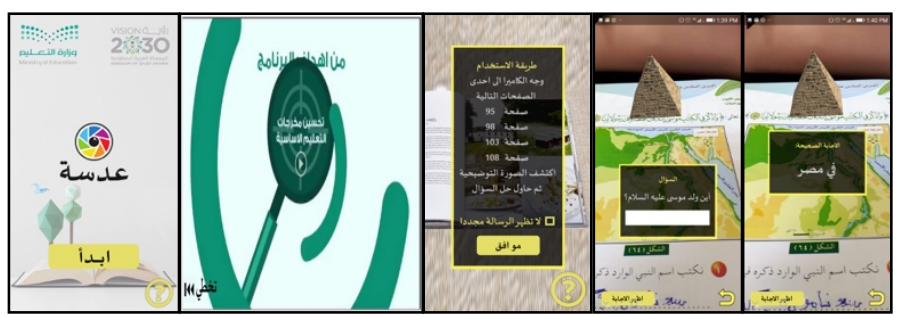

Fig. 5. Interfaces 
Descriptive Statistics As shown in Table 3, the mean of pre-testing was 2.5 (SD = 1.377), also themean of post-testing was $3.30(\mathrm{SD}=.791)$.

Table 3. Paired Samples Statistics

\begin{tabular}{|l|l|c|c|c|c|}
\hline & & Mean & N & Std. Deviation & Std. Error Mean \\
\hline \multirow{2}{*}{ Pair 1 } & Score_Pre_test & 2.50 & 40 & 1.377 & .218 \\
\cline { 2 - 6 } & Score_Post_Test & 3.30 & 40 & .791 & .125 \\
\hline
\end{tabular}

Paired t-test: From this row observe the $\mathrm{t}$ statistic, $\mathrm{t}=-4.451$, and $\mathrm{P}$-value $=0.000$; a very small probability of this result occurring by chance, under the Null Hypothesis of no difference. The Null Hypothesis is rejected, since $p<0.05$ (in fact $p=0.000$ ). See Table 4.

Table 4. Paired Samples Test

\begin{tabular}{|c|c|c|c|c|c|c|c|c|c|}
\hline & \multicolumn{5}{|c|}{ Paired Differences } & \multirow{3}{*}{$\mathbf{t}$} & \multirow{3}{*}{ df } & \multirow{3}{*}{$\begin{array}{l}\text { Sig. (2- } \\
\text { tailed) }\end{array}$} \\
\hline & & \multirow[b]{2}{*}{ Mean } & \multirow{2}{*}{$\begin{array}{c}\text { Std. } \\
\text { Deviation }\end{array}$} & \multirow{2}{*}{$\begin{array}{c}\text { Std. Error } \\
\text { Mean }\end{array}$} & \multicolumn{2}{|c|}{$\begin{array}{l}95 \% \text { Confidence } \\
\text { Interval of the } \\
\text { Difference }\end{array}$} & & & \\
\hline & & & & & Lower & Upper & & & \\
\hline Pair 1 & $\begin{array}{l}\text { Score_Pre_test - } \\
\text { Score_Post_Test }\end{array}$ & -.800 & 1.137 & .180 & -1.164 & -.436 & -4.451 & 39 & .000 \\
\hline
\end{tabular}

There is strong evidence $(\mathrm{t}=-4.451, \mathrm{P}$-value $=.000)$ that the teaching intervention improves marks. In this data set, it improved marks, on average, by approximately 2 points. Of course, if we were to take other samples of marks, we could get a 'mean paired difference' in marks different from -.800 . This is why it is important to look at the $95 \%$ Confidence Interval $(95 \% \mathrm{CI})$. The $95 \% \mathrm{CI}$ is from -1.164 to -.436 . This confirms that, although the difference in marks is statistically significant, it is actually relatively small. You would need to consider if this difference in marks is practically important, not just statistically significant.

\section{Conclusion and Future Work}

This application is an assistant tool in schools for teachers and students of fourth elementary school who are taking the subject of "Social and National Education". The main objectives is to let student visualize the prophets' stories to helps them imagine, remember and improve the student's knowledge by asking them questions about the lessons and to get the strong impact of the story in students' soul when they use the application. Hence, the result of this project has contributed to the educational for young children in Saudi Arabia and this lead to the development of knowledge society.

Moreover, to make them enjoy the stories and make it easier for some teachers to explain the lessons. Also, developing and strengthen the national identity of 
individuals and achieve the Saudi Vision 2030 by enhancing "National Character Enrichment" program that is one of the 2030 Vision programs.

The application developed is able to assist the teachers as an educational tool in teaching at elementary schools in Saudi Arabia. Thus, we recommend this application to be used in all elementary schools in Saudi Arabia as an educational tool in order to encourage the learning process among young children.

The limitation of this project is the appropriateness of this application as an education application is not yet discover and as a result in the future, we are targeted to facilitate the rubrics developed by Papadakis, Kalogiannakis, \& Zaranis (2018) in our application in order to developmentally appropriate education application. Moreover, this AR application could be implementing for other subjects in elementary schools to motivate the students in their learning process. Furthermore, students will involve in learning process and encourage them to read books as the books are more interactive. Besides, this application also provides teachers with more helpful learning tool. Therefore, with this application we intend to improve the learning outcomes in Kingdom of Saudi Arabia that is one of the 2030 Vision program goals called "National Character Enrichment" program.

\section{$7 \quad$ References}

[1] Saudi Vision 2030, "Vision 2030 Kingdom of Saudi Arabia," 2019. [Online]. Available: https://vision2030.gov.sa/en. [Accessed: 19-Nov-2019].

[2] M. Kalogiannakis and S. Papadakis, "AN EVALUATION OF GREEK EDUCATIONAL ANDROID APPS FOR PRESCHOOLERS," in Research, Practice and Collaboration in Science Education (Proceedings of ESERA 2017), 2017.

[3] S. Papadakis, M. Kalogiannakis, and N. Zaranis, "Designing and creating an educational app rubric for preschool teachers," Educ. Inf. Technol., vol. 22, no. 6, pp. 3147-3165, 2017. https://doi.org/10.1007/s10639-017-9579-0

[4] M. Forehand, "Bloom's Taxonomy of Learning Domains: The Cognitive Domain," Emerg. Perspect. Learn. teaching, Technol., vol. 41, no. 4, pp. 47-56, 2010.

[5] R.-R. Rasalingam, B. Muniandy, and R. R. Rasalingam, "Exploring the Application of Augmented Reality Technology in Early Childhood Classroom in Malaysia," 2014. https:// doi.org/10.9790/7388-04543340

[6] K. F. Hew and T. Brush, "Integrating technology into K-12 teaching and learning: Current knowledge gaps and recommendations for future research," Educ. Technol. Res. Dev., vol. 55, no. 3, pp. 223-252, 2007. https://doi.org/10.1007/s11423-006-9022-5

[7] K. Lee, "Augmented Reality in Education and Training," TechTrends, vol. 56, no. 2, pp. 13-21, 2012.

[8] M. Billinghurst, H. Kato, and I. Poupyrev, "The MagicBook: A transitional AR interface," Comput. Graph., vol. 25, no. 5, pp. 745-753, 2001. https://doi.org/10.1016/s0097-8493 (01)00117-0

[9] D. Nincarean, M. B. Alia, N. D. A. Halim, and M. H. A. Rahman, "Mobile Augmented Reality: The Potential for Education," Procedia - Soc. Behav. Sci., vol. 103, no. October 2015, pp. 657-664, 2013. https://doi.org/10.1016/j.sbspro.2013.10.385

[10] P. A. Rauschnabel, R. Felix, and C. Hinsch, "Augmented reality marketing: How mobile AR-apps can improve brands through inspiration,” J. Retail. Consum. Serv., vol. 49, no. March, pp. 43-53, 2019. https://doi.org/10.1016/j.jretconser.2019.03.004 
[11] P. A. Rauschnabel, A. Rossmann, and M. C. tom Dieck, "An adoption framework for mobile augmented reality games: The case of Pokémon Go," Comput. Human Behav., vol. 76, no. July, pp. 276-286, 2017. https://doi.org/10.1016/j.chb.2017.07.030

[12] T. Hilken, K. de Ruyter, M. Chylinski, D. Mahr, and D. I. Keeling, "Augmenting the eye of the beholder: exploring the strategic potential of augmented reality to enhance online service experiences," J. Acad. Mark. Sci., vol. 45, no. 6, pp. 884-905, 2017. https://doi. org/10.1007/s11747-017-0541-x

[13] A. Poushneh, "Augmented reality in retail: A trade-off between user's control of access to personal information and augmentation quality," J. Retail. Consum. Serv., vol. 41, no. October, pp. 169-176, 2018. https://doi.org/10.1016/j.jretconser.2017.12.010

[14] M. Meißner, J. Pfeiffer, T. Pfeiffer, and H. Oppewal, "Combining virtual reality and mobile eye tracking to provide a naturalistic experimental environment for shopper research,” J. Bus. Res., vol. 100, no. March, pp. 445-458, 2019. https://doi.org/10.1016/j. jbusres.2017.09.028

[15] H. Chen, Y. Dai, H. Meng, Y. Chen, and T. Li, "Understanding the Characteristics of Mobile Augmented Reality Applications," Proc. - 2018 IEEE Int. Symp. Perform. Anal. Syst. Software, ISPASS 2018, no. April, pp. 128-138, 2018. https://doi.org/10.1109/ispass. 2018.00026

[16] B. S. Bloom and D. R. Krathwohl, "Taxonomy of educational objectives: The classification of educational goals, by a committee of college and univesity examiners," Handbook 1: Cognitive domain. p. 10, 1956.

[17] A. Fritz, "Want an app to help see eclipses, comets and constellations? This is my favorite. - The Washington Post," 2017. .

[18] J. Kenisky, "Zoo-ar," ZOO-AR, INC. (ZAR), 2012. [Online]. Available: zooar.com/blog.html\%0D.

[19] C. James, "Aug That - Carmen James - Blog at EdLab, TC," 2014. .

[20] D. Raths, "Augmented and Virtual Reality: Where Is the Educational Value? -- THE Journal," 2016. .

[21] “AR-3D Science - Apps on Google Play,” Panther Studio, 2017. .

[22] “AR Flashcards Review | Educational App Store,” AR Flashcards, 2018. .

[23] C. (C) 1999-2019 SurveyMonkey, "SurveyMonkey," 2019. [Online]. Available: https://www.surveymonkey.com/

[24] "Unity for all," 2019. [Online]. Available https:/unity.com/

[25] Developer Portal, "Vuforia developer library," 2019. [Online]. Available: https://library.vuforia.com/

[26] "Design Phase - ZMQ Development," ZMQ Development, 2019. .

[27] Maryland, "Phase 5: Design - Custom Single Release Project," Technology, Maryland department of information, 2009. .

[28] J. Arnowitz, M. Arent, and N. Berger, Effective prototyping for software makers. Elsevier, 2007. https://doi.org/10.1016/b978-012088568-8/50003-5

[29] E. Tiong et al., "The economies and dimensionality of prototyping: Value, time, cost and fidelity,” Proc. ASME Des. Eng. Tech. Conf., vol. 7, no. August, 2018.

[30] R. Elmasri and S. B. Navathe, Fundamentals of Database Systems, 6th ed. Addison Wesley Publishing Company, 2010.

[31] B. Shneiderman, C. Plaisant, M. Cohen, S. Jacobs, N. Elmqvist, and N. A. Diakopoulos, Designing the User Interface: Strategies for Effective Human-Computer Interaction, 6th ed. Pearson Education, 2016.

[32] S. W. Ambler, "User Interface Design Tips, Techniques, and Principles," Ambysoft Inc., 2014. [Online]. Available: http://www.ambysoft.com/essays/userInterfaceDesign.html. 
[33] S. Nidhra and J. Dondeti, "Black Box and White Box Testing Techniques - A Literature Review,” Int. J. Embed. Syst. Appl., vol. 2, no. 2, pp. 29-50, 2012. https://doi.org/10.5121/ ijesa.2012.2204

[34] K. Yeager, "LibGuides: SPSS Tutorials: Paired Samples t Test," 2013.

[35] S. Papadakis, M. Kalogiannakis, and N. Zaranis, "Designing and creating an educational app rubric for preschool teachers," Educ. Inf. Technol., vol. 22, no. 6, p. Educ. Inf. Technol., 2018. https://doi.org/10.1007/s10639-017-9579-0

\section{Authors}

Nahla Aljojo obtained her $\mathrm{PhD}$ in Computing at Portsmouth University. She was Associate Professor at Faculty of Computing and Information Technology - Information System Department - King AbdulAziz University, Jeddah, Saudi Arabia. She is working currently as Associate Professor at College of Computer science and Engineering, Information system and information Technology Department, University of Jeddah, Jeddah, Saudi Arabia. Her research interests include adaptivity in web-based Educational Systems, E-business, leadership's studies, information security and Data Integrity, E-Learning, Education, and Machine Learning (e-mail: nmaljojo@uj.edu.sa)

Asmaa Munshi is an Assistance professor in Cybersecurity Department at College of Computer science and Engineering in University of Jeddah. She is currently serving as a supervisor of Cybersecurity Department, University of Jeddah. Her research interest includes: Educational Technology, E-learning, Information Security and Data Integrity (email: ammunshi@uj.edu.sa).

Azida Zainol is an Assistant Professor at Department of Software Engineering, University of Jeddah, Jeddah. Her research interests are software engineering, requirements engineering, software security and software modelling and software quality assurance (e-mail: azzainol@uj.edu.sa).

Jamal Qadah is lecturer at Faculty of Environmental Design Urban \& Regional Planning Department, King Abdulaziz University, Jeddah, Saudi Arabia (e-mail: jhqadah@kau.edu.sa)

Rahaf Al-Amri is student at College of Computer science and Engineering, Information system Department, University of Jeddah, Jeddah, Saudi Arabia (e-mail: rah14234@gmail.com)

Anan Al-Aqeel is student at College of Computer science and Engineering, Information system Department, University of Jeddah, Jeddah, Saudi Arabia (e-mail: Anan.ageel@hotmail.com )

Maram Al-khaldi is student at College of Computer science and Engineering, Information system Department, University of Jeddah, Jeddah, Saudi Arabia (e-mail: maram00za@gmail.com)

Manar Khattabi is student at College of Computer science and Engineering, Information system Department, University of Jeddah, Jeddah, Saudi Arabia (e-mail: manar.khattabi7@gmail.com)

Article submitted 2019-09-22. Resubmitted 2019-11-22. Final acceptance 2019-11-23. Final version published as submitted by the authors. 